\title{
Maturity Assessment of Hospital Information Systems Based on Electronic Medical Record Adoption Model (EMRAM)- Private Hospital Cases in Iran
}

\author{
Masarat Ayat ${ }^{*}$, Mohammad Sharifi ${ }^{2}$ \\ ${ }^{1}$ Department of IT and Computer Engineering, Payame Noor University, Tehran, Iran \\ ${ }^{2}$ Assistant Professor and Senior IT Consultant, Tehran, Iran \\ Email: ^dr_m.ayat@yahoo.com
}

How to cite this paper: Ayat, M. and Sharifi, M. (2016) Maturity Assessment of Hospital Information Systems Based on Electronic Medical Record Adoption Model (EMRAM)-Private Hospital Cases in Iran Int. J. Communications, Network and System Sciences, 9, 471-477.

http://dx.doi.org/10.4236/ijens.2016.911038

Received: September 10, 2016

Accepted: November 8, 2016

Published: November 11, 2016

Copyright $\odot 2016$ by authors and Scientific Research Publishing Inc. This work is licensed under the Creative Commons Attribution International License (CC BY 4.0).

http://creativecommons.org/licenses/by/4.0/ (c) (i) Open Access

\section{Abstract}

Introduction: Today, information technology is considered as an important national development principle in each country which is applied in different fields. Health care as a whole and the hospitals could be regarded as a field and organizations with most remarkable IT applications respectively. Although different benchmarks and frameworks have been developed to assess different aspects of Hospital Information Systems (HISs) by various researchers, there is not any suitable reference model yet to benchmark HIS in the world. Electronic Medical Record Adoption Model (EMRAM) has been currently presented and is globally well-known to benchmark the rate of HIS utilization in the hospitals. Notwithstanding, this model has not been introduced in Iran so far. Methods: This research was carried out based on an applied descriptive method in three private hospitals of Isfahan-one of the most important provinces of Iran-in the year 2015. The purpose of this study was to investigate IT utilization stage in three selected private hospitals. Conclusion: The findings revealed that HIS is not at the center of concern in studied hospitals and is in the first maturity stage in accordance with EMRAM. However, hospital managers are enforced and under the pressure of different beneficiaries including insurance companies to improve their HIS. Therefore, it could be concluded that these types of hospitals are still far away from desirable conditions and need to enhance their IT utilization stage significantly.

\section{Keywords}

Hospital Information System, Electronic Medical Record Adoption Model, Esfahan, Iran 


\section{Introduction}

Hospital Information Systems (HISs) assist hospital managers to overcome their extensive challenges such as operational costs, process rationalizations, secure information exchange, better claims' management, drug e-prescription, better quality management, and patient awareness [1] [2] [3] [4]. The importance of hospitals' e-health utilization is more recognizable when it is seen that extensive complexity of health care environment along with multi aspect operation of each patient, causes high level of mistakes occurred by hospital personnel particularly managers [5]. As an example, referring the latest research in this area in Iran, the average mistakes of drug prescription done by the nurses in selected hospitals were 19.5 per nurse in a period of three months, which is higher than similar cases in other countries [6]. On the other hand, factors like the shortage of e-health comprehensive standard [7] [8], high costs of e-health implementation [7] [9], high e-health training costs [10] and so on, have led e-health technology to be less developed and stand at lower level compared to other e-technologies such as e-banking, e-education and e-auction in Iran [11] [12]. Nevertheless, different forms of e-health utilization in hospitals is increasing [13] and similarly hospital authorities are more and more interested in applying this technology due to its outstanding impact on health care quality improvement and also medical operational obligations [14] [15]. As an example, the American association of hospitals has estimated that $46 \%$ of American hospitals are currently using information technology at the average and high level.

However, different models and frameworks have been proposed to identify the facilities and defects of HISs in the hospitals; nonetheless, they are mainly pure and not empirical research. Therefore, Healthcare Information and Management Systems Society (HIMSS) which was formerly known as the society of hospital management systems and has particularly focused on worldwide strategic establishment of the idea of optimal utilization of IT and HISs in hospitals, has proposed an HIS maturity assessment model for hospitals. This model has been recognized as Electronic Medical Record Adoption Model (EMRAM) [16]. This valuable model aims at measurement of e-Health services' maturity level in the hospitals and categorizes their HISs from zero to seven stages (Table 1) [16].

Applying this model for assessment of HISs is increasing in the world. Referring to HIMSS website [16], limited hospitals in North America and Europe have reached $7^{\text {th }}$ stage of this model (as an example only one hospital in Spain has achieved stage 7). Furthermore, there is not any $7^{\text {th }}$ stage hospital in the Middle East; but some UAE countries and also Saudi Arabia have reached stage six showing the increasing progress of HISs in the hospitals of those countries [16]. Hence, this paper first of all introduces EMRAM and then focuses on the methodology of current research. Thereafter, the situation of selected private hospitals in Iran is investigated and finally, the results of assessments are presented.

\section{Electronic Medical Record Adoption Model}

HIS is a comprehensive application used to integrate patient's information and to send them to different wards and centers with the purpose of rapid exchange of health care 
Table 1. Stages and specifications of electronic medical record adoption model [16].

\begin{tabular}{cl}
\hline Stage & \multicolumn{1}{c}{ Cumulative capabilities } \\
\hline Stage 7 & $\begin{array}{l}\text { Complete EMR; CCD transactions to share data; Data warehousing; Data continuity with } \\
\text { ED, ambulatory, OP }\end{array}$ \\
Stage 6 & $\begin{array}{l}\text { Physician documentation (structured templates), full CDSS (variance \& compliance), full } \\
\text { R-PACS }\end{array}$ \\
Stage 5 & Closed loop medication administration \\
Stage 4 & CPOE, Clinical Decision Support (clinical protocols) \\
Stage 3 & $\begin{array}{l}\text { Nursing/clinical documentation (flow sheets), CDSS (error checking), PACS available } \\
\text { outside Radiology }\end{array}$ \\
Stage 2 & CDR, Controlled Medical Vocabulary, CDS, may have Document Imaging; HIE capable \\
Stage 1 & Ancillaries-Lab, Rad, Pharmacy-All Installed \\
Stage 0 & All Three Ancillaries Not Installed
\end{tabular}

information, quality improvement, satisfaction increase and cost reduction [17]. Assessing HIS capabilities and requirements, EMRAM is proposed to rank hospitals in different stages starting from 0 to 7 [18]. This model which was introduced by Health Information Management and Systems' Association in 2006, verifies digital capabilities starting from Clinical Data Repository (CDR) up to all activities' documentation in hospitals [19].

This model as a matured model for HISs assessment in hospitals is presently using all over the world [15]. This eight stage model lets hospital authorities to analyze their HIS capabilities and compare their progress with other hospitals and countries [20]. As a result, a suitable method to benchmark hospitals [21] is provided. This method has been applied in over 5500 hospitals in the world until now [22]. Despite these capabilities and advantages, this model is still unknown in various countries, particularly developing part of the world like Iran.

\section{Research Methodology}

In order to evaluate the maturity of HISs in accordance with EMRAM model, three private hospitals were selected in Isfahan province. Isfahan is one of the most important provinces located at the center of Iran where some famous medical doctors present. The hospitals are also among the most famous hospitals in Iran. These hospitals have 80 to 100 beds on average and are called general hospitals.

The HISs in each hospital is taken from private companies. It was interesting that one hospital had no full time staff to administrate their HIS and was just benefited from remote administration offered by their contractor. In other hospitals the situation was nearly the same and as a result only one full time staff was found over there. Interview was carried out as a qualitative research instrument, was applied in this research for data collection. To do so, a checklist was provided in accordance with EMRAM expectations, which was evaluated by experts from health IT sector of related universities and 
hospitals. Moreover, an open interview with IT staff and HIS software developers was arranged to uncover e-Health progress challenges in health care organizations as well.

The data gathering method is described as following. At first, required permission was received from hospital authorities to enter respective hospitals and assess their HISs. Thereafter, final checklist was provided and attempts were made to fill it using interviewees' comments and ideas. It is notable that in one case, there was no IT center in the hospital and because of that researchers had to go to contractor office for interview. The final results of these interviews are presented in Table 2. It is should be mentioned that Zero stage was eliminated from the table due to accomplishment of this stage by all HISs in respective hospitals.

According to Table 2, only two hospitals covered second stage of EMRAM and

Table 2. HIS maturity of private hospitals in accordance with EMRAM expectations.

\begin{tabular}{|c|c|c|c|c|}
\hline Stage & Cumulative capabilities & $A$ & $B$ & $C$ \\
\hline 1 & All three ancillaries (Laboratory, Radiology, Pharmacy) are installed & $\checkmark$ & $\checkmark$ & $\checkmark$ \\
\hline \multirow{4}{*}{2} & Clinical Data Repository (CDR) is available & $\checkmark$ & $\checkmark$ & $\checkmark$ \\
\hline & $\begin{array}{l}\text { Controlled Medical Vocabulary and Clinical Decision Support/Rules (CDS) Engine } \\
\text { (rudimentary) is there }\end{array}$ & $\checkmark$ & $\checkmark$ & $\checkmark$ \\
\hline & Document Imaging (May be) is available & $\checkmark$ & * & $\checkmark$ \\
\hline & $\begin{array}{l}\text { Health Information Exchange (HIE) Capable with other health care providers (May be) is } \\
\text { available }\end{array}$ & $\checkmark$ & $\checkmark$ & $\checkmark$ \\
\hline \multirow{5}{*}{3} & Nursing/Clinical (vital signs, flow sheets, nursing notes) documentation is available & $\checkmark$ & $\checkmark$ & $\checkmark$ \\
\hline & The Electronic Medication Administration Record (EMAR) application is implemented & * & * & * \\
\hline & CDSS (drug/drug, drug/food, drug/lab conflict checking) is available & * & * & * \\
\hline & PACS is available outside of Radiology & * & * & * \\
\hline & Computerized Practitioner Order Entry (CPOE) for use by any clinician is available & * & * & * \\
\hline 4 & $\begin{array}{l}\text { Second Level of Clinical Decision Support (related to evidence based medicine protocols) } \\
\text { is available }\end{array}$ & * & * & * \\
\hline 5 & $\begin{array}{l}\text { Closed loop medication administration (A full complement of radiology) PACS system is } \\
\text { there }\end{array}$ & * & * & * \\
\hline \multirow{4}{*}{6} & $\begin{array}{l}\text { Full physician documentation with structured templates and discrete data (for at least one } \\
\text { inpatient care service area) is implemented }\end{array}$ & * & * & * \\
\hline & Full (level 3) of CDSS (protocols and outcomes) is available & * & * & * \\
\hline & The closed loop medication administration is implemented & * & * & * \\
\hline & $\begin{array}{l}\text { Complete EMR (Mixture of discrete data, document images, and medical images) is } \\
\text { available }\end{array}$ & * & * & * \\
\hline \multirow[t]{3}{*}{7} & $\begin{array}{l}\text { Data warehousing (patterns of clinical data to improve quality of care and patient safety } \\
\text { and care delivery efficiency) is available }\end{array}$ & * & * & * \\
\hline & Clinical information (i.e. CCD) can be readily shared & * & * & * \\
\hline & The hospital demonstrates summary data continuity for all hospital services & * & * & * \\
\hline
\end{tabular}


surprisingly one hospital did not cover any of expectations of this stage. These findings simply reveal the huge weakness of HISs in private hospitals in Isfahan.

\section{Results and Propositions}

It is obvious that hospitals play a crucial role and are presumed as the heart of health care systems in each country. Likewise, HISs in a hospital are considered as a mean of data transportation, decision facilitation and service quality improvement. Therefore, it is indispensable for all health care authorities particularly hospital managers to focus on HIS improvement in the hospitals. At present, EMRAM is considered as a de-facto model to assess HIS maturities in the hospitals all over the world.

Looking at Table 2, the maturity stage of HISs in private hospitals is exposed. The findings of this study disclose the fact that HISs are still lagging and quite weak in private hospitals. The comparison of these hospitals' situation with similar hospitals in other countries, gives a clearer view for the readers. According to HIMSS [22], in Asia, only two hospitals have reached $7^{\text {th }}$ stage of EMRAM and 27 hospitals from Malaysia, India, China, Chinese Taipei, Singapore, Saudi Arabia and UAE have reached $6^{\text {th }}$ stage of EMRAM. While, in Europe, three and 42 hospitals have reached $7^{\text {th }}$ and $6^{\text {th }}$ stages respectively. Of course, there are plenty of hospitals located at lower stages both in Asia and Europe which is not mentioned in this website. Meanwhile, the situation of USA is clearer than other parts of the world due to the fact that USA is the emerging source of EMRAM and it is obviously extending more rapidly too. In more detail, HIMSS [22] [23] uncovers that $3.2 \%$ of the hospitals in USA are in stage $7,15 \%$ in stages 4 and 6,27.5\% stages in 5,25.4\% in stage 3,5.9\% in stage 2, 2.8\% in stage 1 and finally $4.9 \%$ in stage 0 out of 5447 hospitals in this country. These statistics precisely underline huge difference of HIS maturity of Iranian hospitals with other countries, particularly USA.

Referring to above results and in order to mitigate the weaknesses of HISs in Iranian hospitals, following recommendations were proposed by professional experts who were interviewed in this research:

- Professional teams should be formed to make clear strategy to emerge e-health in the hospitals, particularly private hospitals at the ministry level.

- E-health necessities and requirements should be defined in accordance with EMRAM model and current situation of countries' infrastructure. These necessities and requirements must be shared with HIS suppliers and sellers.

- Private hospital managers have to obey the e-health ministry requirements. To materialize this, obligatory rules and regulations should be made at the ministry level.

- The selection of HIS suppliers and sellers should be competence oriented and based on a clear centralized framework and investigation regulation.

- IT centers and units should be benefited from educated and professional human resources. Additionally, a consultation committee contributed to IT staffs of pioneer hospitals and equipped with e-health applications should be created in each province in order to lead other hospitals in this regard as well. 


\section{Acknowledgements}

The financial support of the research council of Payame Noor University of Isfahan is gratefully acknowledged.

\section{References}

[1] Varshney, U. (2009) Pervasive Healthcare Computing: EMR/EHR, Wireless and Health Monitoring. Springer Science and Business Media. http://dx.doi.org/10.1007/978-1-4419-0215-3

[2] Chen, Y.-J. (2002) E-Health: Transforming the Physician/Patient Relationship. Journal of Allied Health, 31, 186.

[3] Wickramasinghe, N.S., Fadlalla, A.M., Geisler, E. and Schaffer, J.L. (2005) A Framework for Assessing E-Health Preparedness. International Journal of Electronic Healthcare, 1, 316334. http://dx.doi.org/10.1504/IJEH.2005.006478

[4] Jennett, P., Jackson, A., Healy, T., Ho, K., Kazanjian, A., Woollard, R., et al. (2003) A Study of a Rural Community's Readiness for Telehealth. Journal of Telemedicine and Telecare, 9 , 259-263. http://dx.doi.org/10.1258/135763303769211265

[5] DeCarvalho, M. and Vieira, A.A. (2002) Erro medico em pacientes hospitalizados. Jornal de Pediatria (Rio J), 78, 261-268.

[6] Julaie, S. (1392) Nurses' Pharmaceutical Mistakes. Research Institute of Nursing Care, School of Paramedical, Iran University of Medical Sciences.

[7] Lorenzi, N.M., Kouroubali, A., Detmer, D.E. and Bloomrosen, M. (2009) How to Successfully Select and Implement Electronic Health Records (EHR) in Small Ambulatory Practice Settings. BMC Medical Informatics and Decision Making, 9, 15. http://dx.doi.org/10.1186/1472-6947-9-15

[8] Pirnejad, H., Bal, R. and Berg, M. (2008) Building an Inter-Organizational Communication Network and Challenges for Preserving Interoperability. International Journal of Medical Informatics, 77, 818-827. http://dx.doi.org/10.1016/j.ijmedinf.2008.05.001

[9] Ferreira, A., Cruz-Correia, R., Chadwick, D. and Antunes, L. (2008) Improving the Implementation of Access Control in EMR. 42nd Annual IEEE International Carnahan Conference on Security Technology.

[10] Richards, H., King, G., Reid, M., Selvaraj, S., McNicol, I., Brebner, E., et al. (2005) Remote Working: Survey of Attitudes to eHealth of Doctors and Nurses in Rural General Practices in the United Kingdom. Family Practice, 22, 2-7. http://dx.doi.org/10.1093/fampra/cmh716

[11] MacKinnon, G. (2009) eHealth in the Commonwealth: Building Healthcare Systems in the Digital Age, Private Sector Perspectives, Opportunities and Challenges in e-Health: Private Sector Perspectives. CBC E-Health Report Commonwealth Business Council, 6-8.

[12] Sharifi, M., Ayat, M., Jahanbakhsh, M., Tavakoli, N., Mokhtari, H. and Wan Ismail, W.K. (2013) E-Health Implementation Challenges in Iranian Medical Centers: A Qualitative Study in Iran. Telemedicine and e-Health, 19, 122-128. http://dx.doi.org/10.1089/tmj.2012.0071

[13] Bates, D.W. and Gawande, A.A. (2003) Improving Safety with Information Technology. New England Journal of Medicine, 348, 2526-2534. http://dx.doi.org/10.1056/NEJMsa020847

[14] Chaudhry, B., Wang, J., Wu, S., Maglione, M., Mojica, W., Roth, E., et al. (2006) Systematic Review: Impact of Health Information Technology on Quality, Efficiency, and Costs of Medical care. Annals of Internal Medicine, 144, 742-752. 
http://dx.doi.org/10.7326/0003-4819-144-10-200605160-00125

[15] Association, A.H. (2007) Continued Progress: Hospital Use of Information Technology. American Hospital Association, Chicago. http://www.aha.org/content/00-10/070227-continuedprogress.pdf

[16] Society HIAMS (2007) 18th Annual HIMSS Leadership Survey, Final Report: Healthcare CIO. www.himss.org/2007survey/docs/18thannualleadershipsurvey.pdf

[17] Mohammadi, M. (1391) The Assessment of Laboratory Information Systems in Educational and Private Hospitals Based on Standards in USA Associations (Isfahan Province Cases).

[18] (2015) Health Canada, Health Care System: eHealth. http://www.hc-sc.gc.ca/hcs-sss/ehealth-esante/index-eng.php

[19] Kazley, A.S. and Ozcan, Y.A. (2007) Organizational and Environmental Determinants of Hospital EMR Adoption: A National Study. Journal of Medical Systems, 31, 375-384. http://dx.doi.org/10.1007/s10916-007-9079-7

[20] Analytics, H. (2015) Details of EMRAM, HIMSS Association. www.himssanalyticsasia.org

[21] Analytics, H. (2015) HIMSS Analytics Middle East, HIMSS Association. http://www.himssme.org/analytics

[22] (2015) Himssanalytics, Annual Study Report, HIMSS Association. http://www.himssanalytics.eu/data/hospitals/annualstudy

[23] Sharifi, M., et al. (2014) The Status of Hospital Information Systems in Iranian Hospitals. Acta Informatica Medica, 22, 268-275. http://dx.doi.org/10.5455/aim.2014.22.268-275

Submit or recommend next manuscript to SCIRP and we will provide best service for you:

Accepting pre-submission inquiries through Email, Facebook, LinkedIn, Twitter, etc. A wide selection of journals (inclusive of 9 subjects, more than 200 journals)

Providing 24-hour high-quality service

User-friendly online submission system

Fair and swift peer-review system

Efficient typesetting and proofreading procedure

Display of the result of downloads and visits, as well as the number of cited articles Maximum dissemination of your research work

Submit your manuscript at: http://papersubmission.scirp.org/

Orcontactijcns@scirp.org 